\title{
Cincuenta sombras de una «mujer habitada» Estudio cualitativo de la trilogía "Cincuenta Sombras de Grey»
}

\author{
Estibaliz Linares Bahillo \\ Universidad de Deusto \\ estibaliz.linares@deusto.es
}

\section{Resumen}

La presente investigación es un estudio cualitativo que analiza la trilogía «Cincuenta Sombras de Grey» con perspectiva de género y mediante una lectura feminista. Del mismo modo, a través del discurso de las propias lectoras, se intenta comprender las claves del éxito conseguido por los libros que la forman. Para ello, la investigación se divide en dos etapas. En la primera, a través de la técnica de análisis de contenido, se detectan y se analizan los mitos del amor romántico, las construcciones sociales estereotipadas y los modelos de género referentes a las relaciones sexuales que aparecen en la trilogía. En la segunda, basándonos en los resultados del análisis de contenido, se realizan dos grupos de discusión, cada uno de los cuales está compuesto por seis mujeres que han leído la trilogía entera (un grupo lo compone mujeres de entre 40 y 50 años, y el otro, jóvenes de entre 16 y 22 años), con el fin de comprender sus motivaciones y sus opiniones respecto a la lectura y detectar los estereotipos de género.

Palabras clave: género; erotismo; mito del amor romántico; maternidad

Abstract. Fifty shades of an inhabited woman: Qualitative study of the Fifty Shades of Grey trilogy

This qualitative research study analyses the Fifty Shades of Grey trilogy from a gender perspective and feminist reading. Additionally, it attempts to understand the keys to the trilogy's success through the discourse of female readers. To achieve this aim, the research is divided into two phases. Using the content analysis method, the first phase focuses on identifying and analyzing the myth of romantic love, stereotypical social structures, and gender stereotypes in terms of sexual relationships within the novel. Based on the results of the analysis, two women's discussion groups are formed in the second phase; each comprising 6 women aged between 16-22 and 40-50 years old who have read this bestselling trilogy. The aim of the discussion groups is to understand the motivations and opinions of these women regarding their reading of the trilogy and identify gender stereotypes.

Keywords: gender; eroticism; myth of romantic love; motherhood 


\section{Sumario}

\begin{tabular}{|c|c|}
\hline Introducción & $\begin{array}{l}\text { Análisis de resultados de los grupos } \\
\text { de discusión }\end{array}$ \\
\hline $\begin{array}{l}\text { Análisis de resultados de la trilogía } \\
\text { "Cincuenta Sombras de Grey» }\end{array}$ & $\begin{array}{l}\text { de discusion } \\
\text { Conclusiones }\end{array}$ \\
\hline Metodología y objetivos & Referencias bibliográficas \\
\hline
\end{tabular}

\section{Introducción}

La trilogía "Cincuenta Sombras de Grey», mediáticamente catalogada como una "novela erótico-romántica» destinada a la liberación sexual de las mujeres, o más vulgarmente descrita como "el porno para mamás», ha sido un superventas en el Reino Unido, Estados Unidos y España, entre otros países (en los primeros cuatro meses, en el Reino Unido, se expendieron 800.000 ejemplares). Así, los libros han sido mencionados por los medios de comunicación internacionales más influyentes, como The Times, la BBC o The Journal, además de por medios de comunicación estatales, como el El Pais o el El Correo (Cincuenta Sombras de Grey, 2014; Lorenci, 2013; Mañana, 2012; Harrow, 2013; "Fifty Shades of Grey found to have herpes in public library», 2013; Lombraña, 2012).

Se ha originado un movimiento social y, con ello, se han creado foros, grupos de Twitter, clubs de fans; se han escrito libros similares a Cincuenta sombras de Grey, como Treinta con Olivia, Pecadores, Diario de una sumisa o Pídeme lo que quieras; se han vendido accesorios y juegos eróticos como los que salen en la novela... Ha sido tan grande el éxito, que la ficción ha sobrepasado a la realidad y, tal y como señala Ibáñez (2013), son muchas las mujeres que acuden a las consultas de sexología interesándose por las prácticas que se narran en el libro (Cincuenta Sombras de Grey, 2014; Lorenci, 2013; Mañana, 2012; "Fifty Shades of Grey found to have herpes in public library», 2013; Lombraña, 2012).

Ante este éxito de ventas y de impacto social, feministas como Michelena (2013) o Fraguero (2013) han realizado su peculiar análisis del fenómeno catalogando a la novela como un "cuento de hadas» que utiliza un sinfín de tópicos femeninos y masculinos que sitúan a la mujer en una situación de vulnerabilidad y sacrificio. Además, el sadomasoquismo es vendido como algo optativo que es envuelto con dosis románticas, ciñéndose al mismo desarrollo lineal y a los mismos protagonistas estereotipados de las novelas rosas. Por otra parte, la universidad de Ohio ha realizado una investigación cualitativa de la trilogía. Dicha investigación determina que este tipo de novelas perpetúan la violencia de género y utilizan una alta carga de violencia simbólica (Bonomi et al., 2013). Así, recogiendo estos últimos argumentos, se ha pretendido realizar una investigación propia y mirar más allá, llevando a cabo un análisis desde la perspectiva de género de la trilogía Cincuenta Sombras de Grey e intentando entender y comprender cuáles fueron los motivos personales de las mujeres que participan en la investigación para comenzar a leer la trilogía y continuar con ella. 
Pero, antes de analizar el contenido de la trilogía y el discurso de las mujeres que participan en esta investigación, es necesario hacer una breve revisión bibliográfica sobre las construcciones de género, el mito del amor romántico y las novelas rosas. Es preciso comprender que las personas somos hereditarias de nuestra educación basada en pares dicotómicos (naturaleza/cultura, doméstico/ público, hogar/trabajo, sentimiento/razón o reproducción/producción) que configuran nuestra identidad de género, tal y como dice Maquiera (2001: 149). Así, mientras que el hombre ha sido asociado a la fuerza, a la razón y al sexo, a la mujer se la relaciona con la pasividad, la delicadeza y el amor.

Esto genera un cosmos basado en atribuciones androcéntricas que condicionan y favorecen la dominación masculina (Bordieu, 2000), lo cual ha producido una jerarquización social donde la mujer se ha visto situada en una posición desigual e invisibilizada. Ello la ha postergado en el ámbito privado. Del mismo modo, Connell entiende que las relaciones de género están dominadas por un imperativo categórico, que es el «dominio del hombre sobre la mujer», siendo el resultado de interacciones y prácticas cotidianas. Así, existe un prototipo ideal de masculinidad y feminidad jerarquizados y dominados por la «masculinidad hegemónica», representada por la autoridad, la fuerza, la resistencia física y, sobre todo, por la heterosexualidad y el matrimonio (Connell, 1995).

En estas consideraciones de género, basadas en la dominación masculina y, por ende, en atribuciones androcéntricas, la construcción de la feminidad estaría ligada a la construcción social de la maternidad (entendida como una institución política de la cual la sociedad se ha valido y se ha aprovechado), ya que, históricamente, el cuerpo reproductivo de la mujer ha desempeñado un papel importante en su socialización (De Beauvoir, 2005; Lagarde, 2011). Ello ha provocado que las mujeres sean caracterizadas como dulces, cariñosas y dependientes (el «ser para otros»). En definitiva, «las buenas madres», que cuidan y se sacrifican para cubrir las necesidades de los demás de manera afectiva (Lagarde, 2011), con lo cual, todas aquellas mujeres que no respondan a estos criterios serán consideradas «malas madres» ${ }^{1} \mathrm{y}$, por tanto, malas mujeres, a las cuales se les atribuye una dimensión irrevocable de «maldad». Lagarde (2011) considera que este grupo lo formarían todas aquellas que ejercen la prostitución, las presas, las lesbianas, las divorciadas, las que abandonan a la prole, las locas o las «madresputas»².

Como se decía, su cuerpo ha desempeñado un papel importante en la valoración y en la construcción de la identidad femenina, tanto que su autoestima y su autoimagen dependen categóricamente de una serie de experiencias y significados respecto a su parte física, con lo cual se convierten en «mujeres objeto». Es decir, sufren una despersonalización, lo que provoca que se

1. Ninguna mujer puede alcanzar el perfil de madre que construye el patriarcado, como ningún hombre puede alcanzar el ideal masculino. Ellas se ven frustradas al no conseguirlo.

2. Estas mujeres viven su maternidad y su profesión como una contradicción perpetua, ya que, según la sociedad patriarcal, la que es madre no es puta, y viceversa. Su rol de madre y su rol de puta, su cuerpo reproductivo y su cuerpo erótico son elementos dispares que no pueden ir acompañando el uno al otro (Lagarde, 2011: 633). 
transformen de ser sujeto a ser objeto (De Beauvoir, 2005). Por tanto, en la dominación cultural masculina, las mujeres dependen directamente de los halagos del hombre, lo cual conlleva que convivan con una peligrosidad, con una dependencia y con un sentimiento de abandono continuos. De este modo, estarán celosas de todo su entorno y convivirán con el miedo por el posible abandono de su compañero.

Además, De Beauvoir (2005) y Lagarde (2011) señalan que las mujeres han representado la virginidad, la pureza, el «no erotismo» y la bondad. Desde el constructivismo, varios autores y autoras, como Michel Focault, Kate Millet, Margaret Mead, etc., han intentado demostrar que el comportamiento sexual se ha visto moldeado a la luz de los condicionamientos sociales y de género, identificando roles sexuales y conductas sexuales duales, así como una que es predominante (la heterosexualidad), siempre basada en la satisfacción masculina (Haeberle, 2005: 71; Martín, 2006). Con ello, las mujeres deben interpretar el papel de sumisas, pasivas, vírgenes, dóciles, tímidas, inexpertas y sexualmente apetecibles; y ellos, por el contrario, tienen que ser dominantes, duros, independientes, egoístas y sexualmente activos (Gutiérrez, 2006: 11; Navarro-Pertusa et al., 2003; Osborne, 1995; Esteban, 2008; Rodríguez, 2010; Haeberle, 2005; Martín, 2006; Forward, 1986: 78-79).

Es evidente que la sexualidad del hombre y la de la mujer son conceptos distintos. Del mismo modo, tal y como explica Lagarde (2011: 239-250), el propio ritual de aprendizaje del juego erótico está en manos de hombres y son las «mujeres malas» las que lo enseñan a sus compañeros.

A causa de estas construcciones interiorizadas y apoyadas por los espacios patriarcales, como puede ser la literatura (Haeberle, 2005: 143), las motivaciones sexuales de ambos géneros están establecidas en la asimetría y en la complementariedad. A ellos les guiarán motivaciones físicas y realizarán justificaciones de oportunidad, mientras que las relaciones de ellas son de afecto (Bordieu, 2000; Esteban, 2008; Navarro-Pertusa et al., 2003). Para Forward (1986: 76), el terreno sexual se convierte en un territorio perfecto para el hombre misógino. Es su espacio de glorificación y satisfacción, uno de los mecanismos mediante el cual adquiere más poder. Cuando penetra a la mujer, él lo vive como un triunfo y ella, como una alienación completa con el hombre. Desde el mismo momento de la erección, la mujer queda como un ser pasivo que debe dejarse penetrar. Es decir, su cuerpo sexuado, su cuerpo erótico, la condiciona (Bordieu, 2000).

Debido a este aprendizaje asimétrico de dominio y sumisión, «se aprende que la dominación es masculina, y la sumisión, femenina» (Lagarde, 2011). Con ello, los comportamientos de la cotidianidad, como son las relaciones sexuales, los ritos, etc., se van transformando a imagen y semejanza de la cultura patriarcal. Para las mujeres, por ejemplo, existen dos momentos clave donde se vuelcan todas las expectativas y los estereotipos depositados sobre sus personas: la maternidad y el casamiento. Ellas viven estos dos momentos con grandes inquietudes, contradicciones y dudas. De esta manera, De Beauvoir (2005: 820) dice que las mujeres enamoradas son «mujeres habitadas», mujeres que se convierten en objetos en manos de hombres. 
Todo ello ha condicionado que el amor se catalogue como análogo a lo femenino, valorado como institución natural de toda mujer, lo que le otorga un poder divino dentro del amor, casi como un espacio de empoderamiento (Herrera, 2010: 112). Así, las mujeres se han criado desde la niñez con la aspiración de "ser TODO para él y que él sea TODO para mí» (Coria, 2001: 51). Las relaciones sentimentales se establecerán como eje central de satisfacción y plenitud para ellas. En el momento en que se establece la relación de pareja heterosexual, se establece un contrato explícito y tácito, donde la mujer toma la responsabilidad de ser la persona dependiente y renunciante, la sacrificada.

Desde pequeñas, se las enseña que el amor es la vía de la felicidad, y se les inculca que sean afables y cariñosas en sus relaciones, una actitud muy similar a la de una madre (Forward, 1986: 57). De este modo, en la sociedad patriarcal, la mujer debe procurar que el amor perdure a través de cuidados y un sinfín de sacrificios personales, de los cuales el hombre se aprovecha (Esteban, 2011: 64; Herrera, 2010: 233; Hite y Colleran, 1989). Así, el amor será valorado según los cuidados procurados por la mujer y comúnmente confundido con la autopostergación (Esteban, 2011: 71). Esto ha llevado a que ellas conformen sus relaciones con los hombres en bases desigualitarias, puesto que su amor es satelital (la mujer "gira y gira» entorno a él) e irá acompañado con palabras como nunca, jamás y siempre (Coria, 2001: 107). Como dice Coria (2001: 93): «El juego del amor es un juego jerarquizado» por patrones sociales.

Por todo ello, muchas son las corrientes científicas, sociológicas, biológicas, psicológicas, entre otras, y desde paradigmas diferentes (esencialismo, relativismo con Michelle Rosaldo, historización con Foucault, o contextualización), que han intentado entender el amor (Esteban, 2011: 45) y, con más o menos acierto, dar una explicación sobre él. Pero este trabajo no pretende criticar a las diferentes fuentes teóricas, ni señalar cuál es la correcta, en el caso de que la hubiera, ni cuál es el verdadero amor o el amor sincero. Hablar de amor es hablar de sentimientos, de personas y de relaciones interpersonales, y generalizar es catalogar. Lo que pretendemos es situarnos en una perspectiva concreta y comprender «el amor». En este caso, para analizar esa construcción, se ha decantado por una perspectiva sociocultural y de género, sin negar que el amor tenga una base fisiológica.

Como dice Esteban (2011: 40), el amor ha adquirido una relevancia simbólica especial en el mundo occidental, hasta el punto en que se ha convertido en eje de nuestra felicidad y de nuestra plenitud. Existe una saturación romántica por parte de los medios de comunicación o de la literatura, que, a su vez, son alimentados por los agentes socializadores más primarios, como la familia o la escuela, lo cual genera una expectativa sobre el amor (Esteban, 2011: 50-52; Forward, 1986: 32). Esteban (2011), Herrera (2010) e Illouiz (2009) entienden este amor como una construcción sociocultural y como una ideología política que establece un orden jerarquizado, donde la mujer se ha situado en las actitudes de sumisión y de dependencia.

Esta ideología del amor se presenta como pensamiento heterosexual, basado en relaciones obligatorias entre hombres y mujeres (tipos de personas antagóni- 
Tabla 1. Mitos del amor romántico

\begin{tabular}{ll}
\hline $\begin{array}{l}\text { Príncipe azul y princesas } \\
\text { maravillosas }\end{array}$ & $\begin{array}{l}\text { Él es el salvador, el valiente y el caballero que salva a la bella pero } \\
\text { débil dama. }\end{array}$ \\
$\begin{array}{l}\text { "Vivieron felices y comieron } \\
\text { perdices» }\end{array}$ & $\begin{array}{l}\text { Con el amor todo es posible. Es lo más próximo a la felicidad } \\
\text { eterna y a la plenitud como mujer. }\end{array}$ \\
Media naranja & $\begin{array}{l}\text { El amor se convierte en la búsqueda de otra persona que te } \\
\text { completa y te representa. Se busca una alineación completa } \\
\text { entre ambos individuos, donde la mujer tiene la responsabilidad } \\
\text { de sacrificar y de hacer renuncias para que la unión sea posible. } \\
\text { Socialmente, el amor significa convertirse en uno solo. }\end{array}$
\end{tabular}

Celos como medida del amor En esta construcción patriarcal del amor romántico, los celos han servido como medida del amor. Tras ellos, se esconden inseguridades, inmadurez y apropiación, porque lo que se busca realmente es la posesión.

Pasión como posesión y control

Se genera la idea de que el amor y la posesión pueden controlarlo y poseerlo todo, incluso a las personas. En el momento en que un individuo que se empareja deja la identidad individual y pasa a ser parte del otro, esto posibilita mecanismos como el control y la posesión.

Exclusividad

Solo va a existir un amor en la vida, y el amor solo se puede sentir hacia una persona.

Fidelidad

Todos los deseos pasionales, eróticos y románticos se deben satisfacer con una sola persona. La monogamia es uno de los valores más potentes dentro del amor romántico occidental.

Omnipotencia

El amor es presentado como el poder mágico que todo lo puede. Este podrá sobrepasar cualquier obstáculo.

Libre albedrío

Compresión de los sentimientos como caracteres internos y exclusivos, que se escapan de toda influencia cultural o social.

Emparejamiento heterosexual Creencia de que el amor es entre una mujer y un hombre. Es lo más natural que puede suceder, y lo que debe suceder.

Matrimonio

El amor se convierte en el mismo fin del matrimonio, es el objetivo final: compartir el resto de tu vida con otra persona. Institución como máxima representación del amor. Todas las historias románticas acaban con este rito.

Fuente: elaborado a partir de Herrera (2010: 294-296), Esteban (2011), Coria (2001), Durbin (1981) y Davis (1981).

Nota: El estudio del INE (2011) recoge que los mitos más comunes entre las mujeres maltratadas son: la media naranja, los celos como posesión, la omnipotencia, el matrimonio, el emparejamiento y la pasión eterna. Entre los hombres maltratadores, en cambio, encontramos los celos y el matrimonio (donde se puede dar la violencia como mecanismo de control).

cas, jerarquizadas y opuestas, pero, a la vez, complementarias). De esta manera, en este "amor romántico», el hombre será representado como la masculinidad hegemónica (completo, universal, independiente) y la mujer se moverá entre parámetros de sumisión y de ser considerada un «objeto» (incompleta, particular, dependiente). El verdadero amor es un amor "hegemónico», donde prima la heterosexualidad, la monogamia y la familia (Esteban, 2011: 48-50; Herrera, 2010: 112). 
El amor romántico es una ideología de género, de clase, de etnia y de sexo, y, como ideología hegemónica, ha sido una institucionalización de sentimientos heterodirigidos (Herrera, 2010: 239). Así, estará dirigido a mujeres blancas, de clase media alta y heterosexuales, pero siempre inferiores al hombre, de manera que se relacionarán con hombres mayores, más poderosos y más fuertes que ellas (Esteban, 2011: 53; Herrera, 2010: 235).

En este sistema de género, se generan una dimensión mítica y, conjuntamente, ciertas creencias que, tras la consulta de varias fuentes, se pueden resumir de la siguiente manera:

Según Herrera (2010: 255), todos estos mitos son modelos patriarcales de dominio y sumisión, donde la mujer se sitúa en la segunda categorización. La mitología romántica es un fiel reflejo de la sociedad patriarcal, que utiliza representaciones simbólicas impregnadas de estereotipos, de modo que «La literatura romántica es la gran escuela del amor» (Herrera, 2010: 211), ya que la autora entiende que este tipo de literatura, que comenzó a coger fuerza en el siglo XIX, con obras tan famosas como la Celestina o Romeo y Julieta, es una herramienta cultural para la sujeción y el subyugo de la mujer, a la cual le era permitido imaginar y soñar mientras permanecía en los estados opresivos del padre o del marido. De este modo, el sustento de toda novela rosa es la dependencia femenina frente a la dominación masculina. Se trata de un contexto de desigualdades que condicionan la situación inferior de la mujer. Ellos son los «ricos burgueses» y ellas, las "pobres» chicas que están buscando su felicidad. Y no les es permitido experimentarla hasta que ellos la encuentran.

En las novelas rosas, siempre se cuentan tragedias, obstáculos, celos, posesión, pero, a pesar de todo ello, el amor y el matrimonio triunfan. Así, el mensaje que se proyecta en ellas es el del amor poderoso, que perdura gracias a sacrificios y espera (Esteban, 2011: 56-58). El amor se convierte en instrumento de salvación, tanto para la mujer como para el hombre (ella libera al hombre de su millonaria pero triste vida, él la salva de la infelicidad). En otras palabras, las novelas rosas se convierten en espejos de los mitos románticos, donde se desenvuelven en guiones cerrados y rápidos (Forward, 1986: 33). Todo ello corresponde a una violencia simbólica que se transmite perpetuamente a través del estilo narrativo (Herrera, 2010: 223), tal y como se representa en el esquema evolutivo que mostramos a continuación:

llustración 1. Esquema evolutivo de las novelas rosas

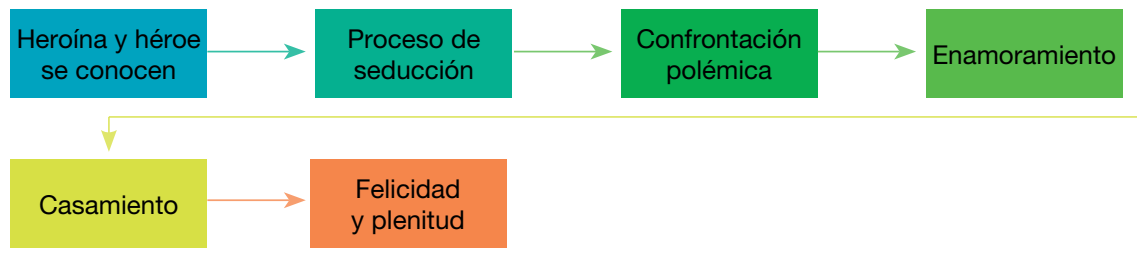

Fuente: elaboración propia a partir de Esteban (2011: 103-104) y Herrera (2010: 253). 
De esta manera, las novelas románticas son las que gozan de mayor preferencia por parte de las mujeres y se trata de las más comercializadas. Según Esteban (2011: 106), en los Estados Unidos y Canadá, es el género más vendido, por delante de los libros de misterio y suspense, con un $24,1 \%$ de lectoras y lectores.

Por todo ello, Herrera (2010: 111-113), Illouiz (2009) y Esteban (2011: 116) entienden que existe una "mercantilización romántica», un amor vendido con fines lucrativos por el capitalismo, donde se busca la creación de una pareja $y$, como consecuencia, una familia proconsumista. La industria occidental se ha aprovechado del ideal romántico y ha utilizado la literatura rosa como empuje para la comercialización. Con ello, el ideal de amor que se ha vendido en las últimas décadas corresponde a un poder político y económico, con el fin, una vez más, de hacer consumir desenfrenadamente.

En conclusión, las novelas románticas o rosas están sustentadas por el capitalismo, donde se proclama la unidad de pareja como unión consumidora. Son libros que utilizan los mismos valores que el capitalismo y el sistema patriarcal. Así, por ejemplo, «el poderoso burgués» podrá comprar a "la bella dama» todo lo que ella desee (Esteban, 2011: 106), lo cual condiciona la dependencia y la sumisión de la mujer.

\section{Hipótesis y marco metodológico}

Una vez realizada una breve revisión bibliográfica que nos ha ayudado a fortalecer la investigación, cuyo objeto de estudio es «analizar desde la perspectiva de género la trilogía "Cincuenta sombras de Grey", así como entender y comprender cuáles fueron los motivos personales de las mujeres para comenzar a leer la trilogía y continuar con ella», las hipótesis previas que guían nuestro estudio son las siguientes:

- El libro Cincuenta sombras de Grey es una novela rosa que utiliza mecanismos patriarcales como los mitos del amor romántico, las construcciones estereotipadas de género y los roles sexuales.

- Gracias a estos mitos, ha tenido tanto éxito entre las mujeres que participaron en los grupos de discusión.

- Este tipo de mitos se siguen dando en las diferentes generaciones y se han acentuado en las chicas jóvenes.

Por tanto, representando gráficamente las hipótesis, se ha podido crear el siguiente cuadro metodológico:

\section{Metodología y objetivos}

Esta investigación está dirigida por una metodología cualitativa. Recordemos que el objetivo general que persigue es la detección y el análisis, desde la perspectiva de género, de las relaciones de dominio y sumisión interpersonales 
Ilustración 2. Cuadro metodológico

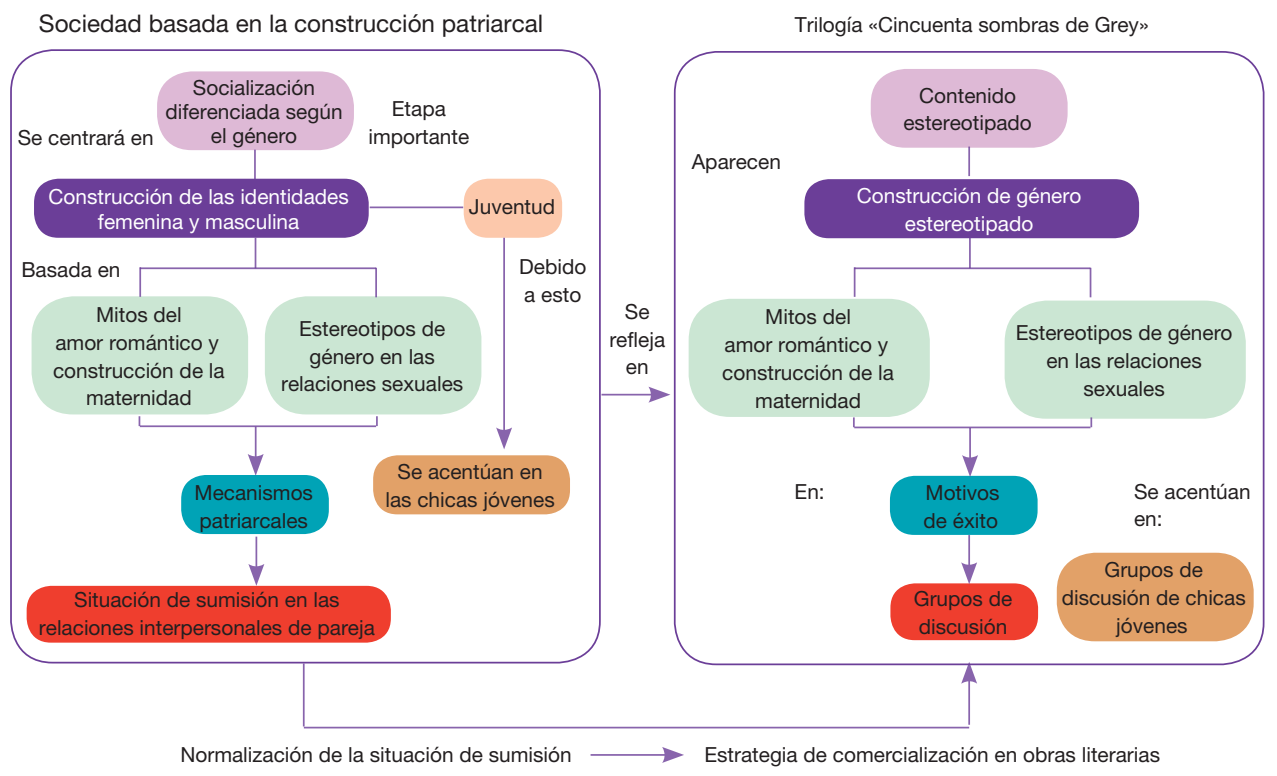

Fuente: elaboración propia.

de pareja que aparecen en la trilogía «Cincuenta Sombras de Grey». Así, intenta explorar y entender la profundidad de lo subjetivo y lo que queda escondido a nuestros ojos e introducirse en él, dejando atrás los juicios de valor y los arraigos personales (Ruiz, 2012a: 44; Taylor y Bogdan, 2000: 19). Con ello, este estudio aporta un marco descriptivo del libro Cincuenta sombras de Grey y la compresión y exploración de las experiencias de mujeres que han leído la trilogía.

Para alcanzar el objetivo antes mencionado, el examen se ha dividido en dos etapas. La primera recurre a la técnica del análisis de contenido, con el fin de analizar la trilogía de manera cualitativa. Para favorecer la compresión del análisis y la investigación, se han escogido fragmentos de los libros que han sido previamente seleccionados y que tienen relación con los objetivos específicos marcados. Son los siguientes:

- Detectar y analizar los mitos del amor romántico.

- Detectar y analizar los estereotipos masculinos y femeninos referentes a las relaciones sexuales.

- Detectar y analizar las construcciones sociales estereotipadas.

De esta manera, se han obtenido resultados que han guiado la segunda etapa de la investigación, es decir, la sumersión en el discurso de las lectoras. 
Así, con el fin de profundizar los elementos analizados en la trilogía y de comprender las diferencias en los discursos según los colectivos de edad, se han creado dos grupos de discusión - uno de seis mujeres adultas que tenían entre 40 y 50 años, y otro de seis chicas jóvenes que tenían entre 16 y 22 años-, para su constitución se han realizado unos cuestionarios previos con tres preguntas sencillas que han ayudado a contar con una diversidad de opiniones dentro del mismo equipo ${ }^{3}$. Todo ello es analizado posteriormente a través del análisis de contenido. Por tanto, se puede decir que los objetivos específicos de esta etapa son:

- Entender los motivos que han llevado a las mujeres participantes de los grupos de discusión a comenzar y a continuar con la trilogía.

- Conocer la opinión de las mujeres participantes sobre la trilogía.

- Detectar y analizar si existen diferencias entre los dos grupos de discusión según el grupo de edad al que se pertenezca.

En conclusión, el libro y los grupos de discusión transcritos se entenderán como "escenarios de observación» o como el «interlocutor de una entrevista», de los cuales se debe sacar información (Ruiz, 2012b: 197), y para obtener esta información, los procedimientos constituirán la codificación. Por otra parte, teniendo en cuenta que, en este análisis, se está buscando la compresión de las justificaciones que hacen las mujeres que se han leído la trilogía y, así mismo, trabajar sobre temas muy puntuales, la dinámica de este grupo de discusión será la de una situación argumentativa dirigida que amplía y orienta el discurso para evitar divagaciones y ceñirse a los objetivos, donde, aprovechando la espontaneidad del grupo, se dinamiza con cierta libertad (Gutiérrez, 2008: 37).

\section{Análisis de resultados de la trilogía «Cincuenta Sombras de Grey»}

Con el objetivo de sistematizar los resultados obtenidos del análisis cualitativo realizado sobre la trilogía, se ha decidido dividir el estudio en tres partes; título y portada; protagonistas, y contenido del mismo libro. Por tanto, los resultados logrados son los que se exponen a continuación.

\section{Título y portada}

La novela está contada a través de los ojos de una joven de 22 años. A pesar de esto, la autora, E. L. James (2011a, 2011b y 2011c), eligió como protagonista principal del título al personaje masculino: Grey. Así, se enmarca al libro desde una perspectiva androcéntrica, siendo Grey la medida de todo el desarrollo literario. De la misma manera, la autora, a través de los títulos, quería reflejar la maduración emocional del personaje masculino y su cambio hacia la liber-

3. La convocatoria se realizó a través de las redes sociales, publicando y enviando un evento. 
tad. Esto demuestra que la obra sigue la evolución de novela rosa descrita por Herrera (2010) y Esteban (2011), es decir, el amor ha conseguido liberar y salvar al hombre que estaba sumergido en la oscuridad y la tristeza.

En cuanto a las portadas, la autora ha decidido que sean oscuras, para reflejar precisamente esa "oscuridad que esconde» Grey, y decide poner en primer plano objetos que han sido utilizados como instrumentos de sumisión en el acto sexual: la corbata, las esposas y el antifaz.

\section{Protagonistas}

Como se demuestra, los personajes femeninos que aparecen en esta novela son cuestionados, discriminados y representados como rivales. De todos ellos, solamente Anastasia se encuentra glorificada, puesto que, según los parámetros patriarcales, es la única a la que se le puede considerar una «buena mujer» y una «madresposa deseable». Esto supone una categorización de las mujeres según los parámetros patriarcales y el fomento de la competencia femenina y, por tanto, de la dominación masculina (Bordieu, 2000).

\section{Contenido}

A pesar de ser vendido como un libro erótico, en realidad, responde al guion cerrado de las novelas rosas e integra todas las características propias de este tipo de textos. Así, la obra acaba con un final feliz —el matrimonio y la formación de una familia-, tras haber superado todo tipo de obstáculos, como pueden ser los accidentes provocados por Jack Hyde, las diferentes mujeres que quieren entrometerse en la relación entre ambos, sus propias discusiones, etc. Aun así, como en las novelas rosa, el amor triunfa.

Esta novela está adornada con un sinfín de mitos del amor romántico, como, por ejemplo: la media naranja, los celos y la pasión como características del amor, la exclusividad, el matrimonio, el emparejamiento sexual, el final feliz, el príncipe valiente, las princesas maravillosas y el libre albedrío. De esta manera, se proyecta el amor como un sentimiento incondicional, permanente, irracional, incontrolable y "mágico», y los celos son las reacciones que corroboran este amor (Herrera, 2010: 294-296; Esteban, 2011; Coria, 2001; Durbin, 1981; Davis, 1981).

Por tanto, se trata de una exposición del amor hegemónico, donde se presenta al hombre y a la mujer como seres antagónicos y heterosexuales que se complementan, pero ello sitúa a la protagonista en una situación de inferioridad y sumisión (Esteban, 2011: 53; Herrera, 2010: 235). Así, Anastasia es humilde, discreta, dócil, joven y tierna, mientras que Christian es rico, poderoso, carismático, fuerte, activo, dominante y controlador.

Esta obra cuenta con otro ingrediente indispensable para las novelas rosas de Occidente: la utopía del consumismo (Herrera, 2010: 111-113; Illouiz, 2009; Esteban, 2011: 116), puesto que se convierte en mensajera de una utopía de la realidad social basada en un comportamiento claramente capitalista. 
Tabla 2. Características de las personas que protagonizan las novelas

\begin{tabular}{|c|c|c|}
\hline Protagonista & Perfil & Características \\
\hline \multirow[t]{3}{*}{ Anastasia } & \multirow[t]{3}{*}{$\begin{array}{l}\text { Buena madre, } \\
\text { mujer objeto }\end{array}$} & $\begin{array}{l}\text { Anastasia es nuestra protagonista. Se trata de una joven insegura, inexperta, dócil, } \\
\text { tierna y cariñosa. Gracias a estas características, se convierte en la representatividad } \\
\text { de la feminidad. Según los criterios evaluados por Lagarde (2011), estaría dentro de } \\
\text { esta construcción de buena mujer y, por tanto, sería una «madresposa». }\end{array}$ \\
\hline & & $\begin{array}{l}\text { Además, y siguiendo la teoría elaborada por Simone de Beauvoir (2005), el cuerpo de } \\
\text { Anastasia representa lo que se espera de una mujer: es pura, frágil, débil y cándida. }\end{array}$ \\
\hline & & $\begin{array}{l}\text { En el transcurso de la relación, ella interioriza el proceso de mito de sumisión, por el } \\
\text { cual se siente como un objeto erótico de Grey. Así, solo se ve a través de los ojos de } \\
\text { este y únicamente busca satisfacerlo. }\end{array}$ \\
\hline Christian & $\begin{array}{l}\text { Masculinidad } \\
\text { hegemónica }\end{array}$ & $\begin{array}{l}\text { Al contrario que Anastasia, nuestro protagonista masculino representa la seguridad, la } \\
\text { fuerza, la razón, la autoridad, la actividad y la potencia sexual. Por tanto, Grey sería la } \\
\text { representación de la masculinidad hegemónica de Connell (1995). }\end{array}$ \\
\hline \multirow{3}{*}{$\begin{array}{l}\text { Madre } \\
\text { biológica } \\
\text { de Grey }\end{array}$} & \multirow[t]{3}{*}{$\begin{array}{l}\text { Mala madre, } \\
\text { «madreputa» }\end{array}$} & $\begin{array}{l}\text { La madre biológica de Grey era una mujer drogodependiente que ejercía la prostitu- } \\
\text { ción. Fue víctima de violencia de género y murió asesinada por el padre de Grey. }\end{array}$ \\
\hline & & $\begin{array}{l}\text { De acuerdo con dichas características, entraría dentro de las malas madres de Lagar- } \\
\text { de (2011), ya que se sale de los parámetros establecidos y deseados de lo que se } \\
\text { considera ser una «buena madre» en la ideología patriarcal. Además, caracterizaría a } \\
\text { la «madreputa». }\end{array}$ \\
\hline & & $\begin{array}{l}\text { La novela refleja perfectamente esta incompatibilidad de roles entre el cuerpo repro- } \\
\text { ductivo y el cuerpo erótico. La propia Anastasia la cataloga como «mala madre» por } \\
\text { haber abandonado a su hijo. En los tres libros, siempre que se habla de ella, se hace } \\
\text { mediante connotaciones negativas y culpabilizadoras. }\end{array}$ \\
\hline \multirow[t]{4}{*}{$\begin{array}{l}\text { Señora } \\
\text { Robinson }\end{array}$} & \multirow[t]{4}{*}{$\begin{array}{l}\text { Mala mujer, } \\
\text { «puta» }\end{array}$} & $\begin{array}{l}\text { Esta mujer es representada como la rival de Anastasia. La señora Robinson es «la } \\
\text { otra» y quien enseña e inicia a Grey en el juego erótico basado en el dominio y la } \\
\text { sumisión (Lagarde, 2011). }\end{array}$ \\
\hline & & $\begin{array}{l}\text { Queda totalmente condenada en el libro por haber tenido un pasado común con Grey, } \\
\text { ser quince años mayor que él y estar casada cuando mantuvo relaciones sexuales con } \\
\text { nuestro protagonista. }\end{array}$ \\
\hline & & $\begin{array}{l}\text { Este personaje se proyecta como un obstáculo para la relación entre los dos prota- } \\
\text { gonistas y se observa la lucha de halagos por la valoración masculina (De Beauvoir, } \\
\text { 2005). }\end{array}$ \\
\hline & & $\begin{array}{l}\text { Se debe destacar que la señora Robinson es una mujer maltratada por su marido, pero } \\
\text { prefiere continuar estando casada con él para mantener su estatus social. Se trata de } \\
\text { un personaje frío, con el único interés del beneficio económico. Esto condiciona a pro- } \\
\text { yectar un mensaje erróneo de la violencia de género y a considerar a la mujer como } \\
\text { un ser interesado y ambicioso. }\end{array}$ \\
\hline \multirow[t]{2}{*}{ Leila } & \multirow[t]{2}{*}{$\begin{array}{l}\text { Mala mujer, } \\
\text { «loca» }\end{array}$} & $\begin{array}{l}\text { El caso de Leila sirve para representar la desolación y el «vacío afectivo» (Coria, 2001) } \\
\text { por el que puede pasar una mujer, hasta llevarla a la locura y a tener sentimientos tan } \\
\text { autodestructivos como el suicidio. Esta situación de total desolación y desvalorización } \\
\text { de su propia persona la conduce a un estado de total vulnerabilidad. }\end{array}$ \\
\hline & & $\begin{array}{l}\text { A través de la imagen de Leila, se refleja la frustración femenina causada por la } \\
\text { ausencia del hombre al que desea. Ello supone estar fuera de los parámetros estable- } \\
\text { cidos para su género y ser, por tanto, una mala mujer, más concretamente, una «loca» } \\
\text { (Lagarde, 2011). }\end{array}$ \\
\hline
\end{tabular}

Fuente: elaboración propia. 
Son varios los ejemplos que podríamos enumerar, ya que, cuando la autora describe cada uno de los múltiples regalos que Christian hace a Anastasia, cita marcas comerciales; por ejemplo: Apple, Audi, Louis Vuitton, etc. La novela hace apología de los bienes materiales y de la belleza como criterio de vida y de bienestar.

Por otra parte, y como se decía al inicio, los agentes de publicidad catalogan a esta obra como un texto erótico por su alto contenido sexual. Lo cierto es que introduce varios elementos del erotismo y contextualiza las relaciones íntimas como espacio de dominio y sumisión, puesto que la mujer es el objeto al que se debe subyugar, controlar y dominar. Para describir estas relaciones, la autora se ha basado en tópicos y roles de género (Gutiérrez, 2006: 11; Navarro-Pertusa et al., 2003; Osborne, 1995; Esteban, 2008; Rodríguez, 2010; Haeberle, 2005; Martín, 2006; Forward, 1986: 78-79; Bordieu, 2000). Así, mientras que para Grey el sexo es un mecanismo de posesión y de reivindicación de su virilidad, para Anastasia es la alineación plena con el protagonista de la novela.

Como se percibe, la autora ha construido la sexualidad y los roles sexuales encima de bases androcéntricas (Esteban, 2008; Navarro-Pertusa et al., 2003). Además, en la relación íntima de Christian y Anastasia, se dan espacios de agresión y de violencia de género (ella sufre maltrato físico, psicológico, sexual y económico). La autora trivializa y normaliza estas actitudes sexistas y machistas camuflándolas entre los mitos del amor romántico. Una de las representaciones más machistas con las que nos encontramos en el libro es el contrato de sumisión. Este contrato está basado en parámetros discriminatorios y sexistas que condicionan la vulnerabilidad de la mujer por antonomasia. Además de esto, Christian utiliza los espacios íntimos como reivindicación personal y desahogo de emociones negativas generadas hacia su madre biológica ${ }^{4}$, quien, como se comentaba en la descripción, fue asesinada por su padre. Esto generó en Grey unos fuertes traumas que solo sabe canalizar a través del sexo.

Desde esa construcción de la maternidad interiorizada, a Anastasia le conmueve la historia del abandono sufrido por el protagonista y, en su relación con él, encarna un rol de progenitora. Ella misma se ve como procuradora de cuidados y a él lo considera un niño que la necesita para sobrevivir. De esta manera, durante todo el relato, Anastasia vive un proceso de encajonamiento y modelaje femenino que la lleva a la total sumisión y subyugo respecto a Grey, con lo cual se encierra en una jaula de cristal que constituye su propio cautiverio. Así, cuando ella le abandona o cuando le cuenta que está embarazada ${ }^{5}$, se puede comprobar un "vacío afectivo» dentro de una persona, con lo que se acaba estableciendo una relación satelital (Coria, 2001).

4. Toda la novela exime de culpas a Grey y responsabiliza a las mujeres que han convivido con él, como su madre biológica o la señora Robinson.

5. El momento en que le comunica que está embarazada constituye otro episodio de violencia de género. Este la abandona, le grita, la insulta y la responsabiliza y la culpabiliza de todo lo ocurrido. 
A lo comentado, se debería añadir la especial vulnerabilidad y la gran dependencia que muestran las mujeres de la obra. Todas padecen una subordinación emocional, compiten entre ellas y han sufrido malos tratos o han sido acosadas en el trabajo (como en el caso de Anastasia), con lo que se describe un marco general de la representatividad masculina y femenina, donde la mujer será sinónimo de amor, dependencia, cuidados y sumisión, y adoptará un rol patogénico no violento (Coria, 2001). El hombre, en cambio, será un ser fuerte, independiente, sexual, autoritario y dominante (Herrera, 2010), todo ello combinado con un lenguaje sexista.

En definitiva, es una novela que refleja la construcción patriarcal y el sistema basado en la dominación masculina (Bordieu, 2000). Constituye un espejo de los roles estereotipados que se entraman en la ideología patriarcal, donde se construyen cautiverios y jaulas de cristales irrompibles.

\section{Análisis de resultados de los grupos de discusión}

La información que aparece a continuación no quiere ser generalizable, sino exponer los resultados de los grupos de discusión realizados. Se pretende evitar la homogeneización de las mujeres, ya que cada una es heredera de sus experiencias personales, y estas han marcado su peculiar análisis de la trilogía.

Comenzando por los cuestionarios (se cuenta con una muestra de veinte de ellos), se puede decir que, en ambos grupos de edad, encontramos tanto opiniones a favor de la obra como en contra, es decir, la edad no explica el mayor o menor aprecio por las novelas trabajadas (en cambio, en los grupos de discusión, esto varía, de modo que, como veremos, comienzan a aparecer matices en el discurso). Así pues, mientras que las mujeres a las que les ha gustado la trilogía la califican de romántica, emocional y sentimental, las demás la consideran repetitiva, reiterativa y romántica, y por ello abandonaron su lectura o llegaron al tercer libro «asqueadas». Así, aquellas mujeres a las que les ha gustado optarían por el segundo o por el tercero, ya que en estos se da una evolución sentimental y emocional de los protagonistas, además, se va apreciando el cambio que experimenta Grey. Sin embargo, a aquellas a quienes no les ha gustado, en el caso de elegir uno de los tres, mencionan el primero o el tercero (el primero porque es el que abarca el tema erótico y el tercero porque significa el final de la trilogía y es donde más acción se da).

En cuanto a los grupos de discusión, cabe decir que estas dos perspectivas se proyectan en ambos colectivos, pero, como veremos, las argumentaciones y lo que llamaremos "proceso de desmitificación" variarán según el grupo de edad. Además, cabe decir que todas habían partido del hecho de que se trataba de una novela erótica, ya que el sistema capitalista lo había vendido así. De esta manera, todas coinciden en los argumentos que las llevaron a comenzar la trilogía: "Me lo recomendó una amiga» u "Oí hablar mucho de él y todas las mujeres nos lo estábamos leyendo. Estaba de moda».

Por otro lado, todas, sin excepción, detectaron que se trataba de una novela romántica, más que de una novela erótica, y esto es lo que ha creado la 
diferencia de opiniones. Las mujeres a las que les ha gustado el libro, debido a la construcción y al mito de la maternidad al que estamos expuestas todas nosotras (Lagarde, 2011; Coria, 2001; Esteban, 2011), se han vinculado con el protagonista de Grey, victimizándole e infantilizándole como un «niño que necesita cuidados y afectos por su pasado traumático». Desde esta construcción de la feminidad como procuradora de cuidados y afectos, responsabilizan a Anastasia de las decisiones tomadas, comprendiendo que es una mujer autónoma con un criterio propio, y que es ella misma la que decide seguir con la relación y con los actos sexuales.

Estas lectoras que se han vinculado a Grey y que responsabilizan a Anastasia justifican las agresiones y los maltratos realizados por él. Así mismo, normalizan los mitos del romanticismo y argumentan que «se trata de una bonita novela de amor». Además, aprecian una modificación notoria en la actitud de Grey ("todo por Anastasia») y creen en ese ideal de cambio, de "con amor y sacrificio, un hombre, por muy enfermo que esté, se puede cambiar». Esto último es mucho más evidente por parte de las chicas jóvenes, puesto que una gran parte de este colectivo (de seis, cinco) confía en este cambio, además, tres de ellas tienen totalmente interiorizados los mitos del amor romántico y del amor maternal como sinónimo de sacrificio.

A lo comentado, se debe añadir que las mujeres que parten de esta premisa de la construcción de la maternidad invisibilizan todos los sacrificios realizados por Anastasia y glorifican los actos realizados por Grey. Esto las hace interpretar que se trata de una relación equilibrada y amorosa, donde ambos han conseguido un dominio emocional - esta consideración es una de las causas de la socialización patriarcal, la invisibilización y el encajonamiento continuo de la mujer (Coria, 2001) — y hablan de protección y cuidados hacia la protagonista por parte de Christian. Así mismo, invisibilizarían y normalizarían el proceso de mito de sumisión de De Beauvoir (2005).

Como contraposición a esta perspectiva, dos de las chicas jóvenes y cuatro de las mujeres adultas desmitifican todo el libro y comprenden que se trata de una obra donde los protagonistas adoptan roles totalmente estereotipados según el género. Mientras que Grey sería fuerte, controlador, poderoso y millonario, es decir, una representación fiel de la masculinidad hegemónica de Connell (1995), Anastasia constituiría el reflejo de la mujer objeto (De Beauvoir, 2005) y la madresposa (Lagarde, 2011), es decir, buena, débil, sutil, cautelosa e inexperta.

Estas mujeres, adultas y jóvenes, que se encuentran en esta perspectiva van desmantelando poco a poco todos los mitos y las trampas patriarcales literarias con las que juega el libro. Así, sobre todo las adultas ${ }^{6}$, analizan los mitos de «vivieron felices y comieron perdices», «exclusividad», "onmipotencia», "príncipes y princesas maravillosos», «celos», etc. (Herrera, 2010: 294-296; Esteban, 2011; Coria, 2001; Durbin, 1981; Davis, 1981).

Estas mujeres, al no vincularse a Grey, detectan los sacrificios y el modelaje femenino al que ha tenido que hacer frente Anastasia, y así argumentan que

6. Las jóvenes detectan el mito de los celos y de la omnipotencia. 
se trata de una relación desnivelada y dañina para ella (a este proceso de desmitificación no ha llegado ninguna de las chicas jóvenes). Tres de las mujeres adultas hacen especial hincapié en que se trata de una novela que proyecta una relación de maltrato y violencia de género ${ }^{7}$, y por ello detestan la trilogía.

Cuando las cuatro mujeres adultas desmitifican la novela, entre ellas mismas sucede otra oposición: mientras que, para tres de ellas, es responsabilidad de Anastasia, debido a su carácter débil y sumiso, y afirman que hay «mucha mujer tonta" $\mathrm{y}$ "mujeres con vocación de maltratada»" la cuarta comprende que la educación es la causante de que Anastasia se perciba a sí misma como procuradora de cuidados. Por tanto, se puede concluir que, de todas las mujeres que han participado en ambos debates, solo una realiza una desmitificación completa del libro, puesto que detecta todas las trampas literarias sin caer en prejuicios ni estereotipos.

Como se ha visto, dependiendo de la valoración de la obra que hagan las participantes, la descripción de los protagonistas varía. Con los demás personajes que aparecen en la trilogía, no ocurre lo mismo. Comenzando por la madre biológica de Grey, para las chicas jóvenes, se trata de una mujer sumisa, que ha sido incapaz de cuidar de su hijo. Para las adultas, se trata de una mujer drogodependiente incapaz de cuidar de su hijo y hacerse responsable de sus deberes como procuradora de cuidados y afectos maternos. De este modo, para las jóvenes, es la directa responsable de los traumas de Grey, y las adultas mencionan diferentes factores de la situación personal de Grey.

En cuanto a la señora Robinson, todas la consideran la rival directa de Anastasia. La ven como una mujer dominante y fuerte, que puede hacer frente a la relación de ambos y desestabilizarla. A causa de esta proyección de mujer fuerte y madura, se habla en varias ocasiones de ella. Para unas, ha sido el factor de resiliencia y, para las demás, «la otra». En cualquier caso, todas mencionan la palabra pederasta con connotaciones negativas.

Al contrario de lo que ocurre con la señora Robinson, Leila pasa desapercibida en sus discursos. Cuando se les pregunta por ella, todas coinciden en describirla como una persona sumisa y «loca». Las adultas continúan el debate y acaban señalando que es la proyección de una mujer que ha pasado por una relación de maltrato, que es la imagen del dominio, del control y de la posesión a los que ha estado sometida, así como de la misma dependencia emocional. Todo ello nos lleva a determinar que la rivalidad femenina está muy interiorizada y que es más acentuada en las jóvenes.

Lo mismo ocurre con el erotismo. Todas las mujeres, adultas y jóvenes, en mayor o menor medida, cuentan que han sentido excitación con el libro, lo que nos lleva a concluir que el sistema patriarcal les ha prohibido sentir ese

7. Ninguna de las jóvenes habla de maltrato ni de violencia de género.

8. Tres de las mujeres tienen muy normalizados e interiorizados prejuicios y estereotipos de las relaciones de maltrato y hasta en algunas ocasiones responsabilizan a la mujer por mantener una relación de dominio y sumisión. En ningún momento se ve el problema como algo estructural y colectivo, pero existe un estigma social sobre las mujeres que han sufrido violencia de género, sobre todo violencia doméstica. 
tipo de sensaciones. La publicidad les ha vendido que era «el libro erótico de las mujeres». Así, lo han visto como una oportunidad para liberar su propia imaginación, pero el problema con el que se han encontrado ha sido que se trataba de un erotismo retrógrado y dirigido de manera unidireccional a satisfacer las necesidades masculinas.

Incluso una de las mujeres adultas comenta que nosotras hemos estado encarceladas en nuestros propios cuerpos, que nuestro erotismo no nos ha pertenecido. Todas sus compañeras la apoyan y argumentan que existe una falta de educación sexual que nos enseñe a explorar nuestros cuerpos y a conocernos. En definitiva, a ser dueñas de nosotras mismas. Las jóvenes, en cambio, prefieren no comentar estos temas y evitan hablar de las relaciones íntimas. Se denota que existe un gran tabú interiorizado, el cual hace referencia a esa opresión impuesta (Lagarde, 2011; Gutiérrez, 2006: 11; Navarro-Pertusa et al., 2003; Osborne, 1995; Esteban, 2008; Rodríguez, 2010; Haeberle, 2005; Martín, 2006; Forward, 1986: 78-79; Bordieu, 2000).

Todo lo que se ha comentado — estas relaciones desniveladas de control, posesión y dominio- las mujeres lo ven reflejado en la realidad juvenil, alegando que «existe una involución de valores y retroceso en los roles». En cuanto a las jóvenes, ellas mismas detectan cómo la relación que se proyecta en la trilogía es fácil de externalizar a su realidad, puesto que los chicos se sirven de las nuevas tecnologías para controlarlas. Estas jóvenes cuentan casos graves de dominio y maltrato, pero sin ponerle nombre: «Lo que no se menciona, no existe».

Una de ellas incluso conoce a "un amigo» que se caracteriza como Grey y se siente orgulloso de ello. La joven habla de BDSM (bondage; disciplina y dominación; sumisión, y masoquismo $)^{9}$. Se están instaurando nuevos patrones de comportamientos sexuales en un sistema patriarcal donde aún existen discriminaciones por razón de género y relaciones basadas en el dominio y la sumisión, y la mujer es la que padece las consecuencias de ello.

Esteban (2011), Illouiz (2009) y Herrera (2010) comentan que el sistema capitalista ha utilizado las novelas rosas como instrumentos de difusión del amor romántico. En nuestra época posmoderna, se sigue comercializando con estas novelas, pero, en este caso, se ha utilizado un mecanismo de mercantilización diferente: el erotismo. Al estar estrechamente relacionado con la sociedad patriarcal, este sistema ha comprendido que el erotismo de las mujeres ha sido negado, y utilizando esta escusa, los intereses capitalistas han gobernado y han creado una masa social en nombre de la liberación sexual femenina.

En definitiva, lo que ha pretendido ser este análisis es el espejismo de aquellas mujeres que se sociabilizan en un sistema patriarcal y reflejar que la brecha entre generaciones no hace mella en el análisis crítico, incluso se retrocede y se normalizan muchas más actitudes misóginas y machistas.

9. Las personas que realizan estas prácticas adoptan roles de dominio y sumisión que se basan en relaciones sexuales que están al límite del dolor y del placer. Las dos personas que participen en este tipo de actos sexuales deben estar totalmente de acuerdo y los roles se pueden invertir siempre que se quiera (Domènech y Martí, 2004). 


\section{Conclusiones}

Tras los resultados del análisis cualitativo, se puede establecer que la trilogía «Cincuenta Sombras de Grey» es un reflejo del sistema patriarcal más arcaico y dañino que vulnera los derechos de la mujer. Busca la representación de la feminidad dependiente, sumisa y sutil, y se basa en construcciones sociales estereotipadas para crear un contexto misógino y decadente para ellas, con lo que las coloca en una situación de máxima vulnerabilidad.

De la misma manera, este libro juega con la sobreerotización masculina y femenina, donde ella aparece como una mujer pequeña, muy delgada y débil; y él, como un chico fuerte y poderoso. Las mujeres se construyen la sexualidad y el erotismo en base a este ideal hegemónico, donde incluyen a Grey como mito erótico.

Por otra parte, se ha demostrado que la trilogía fue alimentada y sobredimensionada por el sistema capitalista. Los valores que aparecen en ella son proclives a promover parejas y familias proconsumismo. Así, el sistema capitalista ha utilizado el lema de «la liberación sexual de las mujeres» para crear un movimiento social que le ayude a lograr alcanzar sus intereses comerciales. Lo cierto es que, lejos de poder ser una novela erótica liberadora, se trata de una obra romántica opresiva que tiene por mensaje «Ser TODO para él y que él sea TODO para mí» (Coria, 2001: 51).

Además, esta trilogía realiza una apología directa de las relaciones sexuales estereotipadas basadas en el dominio y la sumisión, con la excusa de que se trata de prácticas sadomasoquistas. Con ello, todo el aprendizaje erótico y la evolución de la relación sexual de los protagonistas se basa en una perspectiva androcéntrica dirigida únicamente a satisfacer los deseos masculinos.

Todo lo comentado es analizado por las participantes según percepciones divergentes. Sin ánimo de generalizar, ya que cada una hace su peculiar análisis de la trilogía, se puede decir que no todas las hipótesis planteadas al inicio se cumplen y, tras el estudio realizado, se esclarecen nuevas conjeturas, como, por ejemplo, la interiorización de construcciones patriarcales potentes, como el mito de la maternidad y la rivalidad femenina. En cuanto a los mitos del amor romántico, la hipótesis se afirma y se puede decir que estos están más normalizados por parte de las chicas jóvenes, pero no se puede garantizar que sean el motivo del éxito de ventas. Como ya se ha afirmado, las mujeres consideran que este ha sido debido al propio marketing.

A pesar de contar con participantes que tienen interiorizados estos estilos de comportamiento estereotipados, han formado parte de estos grupos mujeres adultas y jóvenes que parten de una perspectiva crítica y desmantelan las trampas literarias, aunque solo una de ellas llega a realizar todo el proceso de desmitificación al completo. Esto denotaría que, aún en nuestro sistema y proceso educativo, existe una decadencia coeducativa ${ }^{10}$, y que las más jóvenes constituyen el colectivo diana de alerta.

10. En esta reflexión, se entiende por coeducación: «Propuesta pedagógica actual para dar respuesta a la reivindicación de la igualdad realizada por la teoría feminista que supone una reformulación del modelo de transmisión de conocimiento y de las ideas desde una perspectiva de género en los espacios destinados a la formación y el aprendizaje» (INE, 2008: 16). 
Otro de los mecanismos patriarcales opresivos que ha relucido en la trilogía ha sido el «erotismo robado» de las mujeres, así como el tabú social con el que nos encontramos para exponer libremente nuestra sexualidad. Esta internalización del erotismo como algo totalmente privado está mucho más marcada en las chicas jóvenes, que se encuentran muy incómodas con el tema del sexo. Se puede concluir que estamos sumergidas y sumergidos en una sociedad inmadura sexualmente e ideológicamente hablando, donde se están normalizando pautas de comportamientos misóginos, dominantes y machistas en el contexto de las relaciones sexuales.

En el caso de las chicas jóvenes, se han comprobado situaciones alarmantes, cargadas de vivencias de violencia de género, control y dominación, sobre todo a través de las nuevas tecnologías, pero que no están siendo percibidas como tales. Por tanto, llegados hasta este punto, la propuesta que se plantea en este estudio es si la coeducación y la coeducación sexual integrada de manera transversal en nuestras escuelas e instituciones académicas sería la solución posible para la prevención de estas situaciones y la detección de contenidos tan machistas como el libro Cincuenta sombras de Grey y, así, poder realizar un proceso de desmitificación completo.

Camps (2010) habla de la ética pública, una ética que tenemos interiorizada dentro de nosotros, una ética común. Pero, en estas últimas décadas, esta ética se ha visto truncada debido a una serie de factores, como, por ejemplo, la globalización. Ahora mismo, las personas no sabemos con exactitud qué es ético y qué no. Es necesario que nos enseñen a criticar y a dudar de lo que vemos. Lo mismo ocurre con la igualdad. Debemos plantearnos nuestros esquemas sociales. Una ciudadanía informada es una ciudadanía crítica, y una ciudanía coeducada es una ciudadanía igualitaria, ya que nos reviste de herramientas de desaprobación y reflexión.

El sexo y el erotismo se deben sacar a la luz, es algo que nos pertenece como seres humanos. Es innegable que existe una condición biológica, pero el sistema oprime la condición de la mitad del mundo. Es necesario ser personas críticas con nuestros patrones de comportamiento, ya que somos hereditarias de nuestro pasado y de nuestra socialización. Lo privado es público.

Nos han arrebatado nuestros cuerpos erotizándolos, nuestro erotismo está a merced de ellos, y nuestro amor ha sido comercializado. Hemos permanecido a la espera de tener suerte y de encontrar a un hombre «bueno» que nos cuide y nos valore. La coeducación debe empezar por aquí. Debemos ser coeducadas situándonos como una parte activa de la sociedad y valorándonos a nosotras mismas como personas, no como seres pertenecientes a otros. Es preciso que conozcamos nuestro cuerpo, que critiquemos nuestros comportamientos y que critiquemos lo que leemos.

Con todo ello, se podría finalizar esta investigación alegando que, cuando éramos pequeñas, nos contaban cuentos de princesas y príncipes y nos invitaban a soñar con mundos ideales y castillos maravillosos. A medida que fuimos creciendo, nos vendieron revistas que cuestionaban nuestros cuerpos y vestimentas, y ahora, que somos más mayores, nos escriben libros que guían 
nuestras relaciones amorosas y sexuales, invitándonos a ser cuerpos de otros y «mujeres habitadas».

El proceso de sociabilización femenina es un duro camino lleno de opresiones culturales y sociales, que nos enseñan a vivir por otros. Así, este libro lleno de guiños patriarcales y machistas es un resquicio más de estos sistemas dañinos para nosotras, donde se nos invita a ser una «tímida, débil y vulnerable mujer habitada».

\section{Referencias bibliográficas}

Beauvoir, Simone de (2005). El segundo sexo. Madrid: Cátedra. Feminismos.

Bonomi, Amy; Altenburger, Lauren E. y Walton, Nicole L. (2013): "'Double Crap!": Abuse and Harmed Identity in Fifty Shades of Grey". Women's Health Magazine [en línea], 22 (9), 733-744. $<$ http://dx.doi.org/10.1089/jwh.2013.4344>.

Bordieu, Pierre (2000). La dominación masculina. Barcelona: Anagrama. Argumentos. CAmps, Victoria (2010). El declive de la ciudadanía: La construcción de una ética pública. Madrid: PPC.

Cincuenta sombras de Grey [en línea], 2014. <http://www.cincuentasombras.com/> [Consulta: 28 abril 2014].

Connell, Raewyn (1995). Masculinities. University of California Press.

Coria, Clara (2001). El amor: No es ni como nos contaron ni como lo inventamos. Buenos Aires: Paidós.

Davis, Kingsley (1981). «Celos y propiedad sexual». En: Clanton, Gordon y SMith, Lynn G. (eds.). Anatomía de los celos. Barcelona: Grijalbo, p. 193-220.

Domènech, Bortemieu y MarTí, Silbil.la (2004). Diccionario multilingüe de BDSM. Barcelona: Bellaterra.

Durbin, Karen (1981). «Sobre los celos sexuales». En: Clanton, Gordon y SMith, Lynn G. (eds.). Anatomía de los celos. Barcelona: Grijalbo, p. 63-77.

Esteban, Mari Luz (2009). «Identidades de género, feminismo, sexualidad y amor: Los cuerpos como agentes». Revistas Cientificas Complutenses: Politica y Sociedad [en línea], 46 (1 y 2), 27-41. <http://revistas.ucm.es/index.php/POSO/article/ view/POSO0909130027A/21836>.

- (2011). Crítica del pensamiento amoroso: Temas contemporáneos. Barcelona: Bellaterra.

EstéBANEZ, Ianire (2010). Te quiero... solo para mi: Relaciones adolescentes de control [en línea]. <https://dialnet.unirioja.es/descarga/articulo/3829792.pdf>

"Fifty Shades of Grey found to have herpes in public library». The Journal [en línea], 15 de noviembre de 2013. <http://thedailyedge.thejournal.ie/fifty-shades-of-greyherpes-1176490-Nov2013> [Consulta: 31 enero 2014].

FraGUERO, Carmen (2013). «Fifty Shades of Grey: Una novela popular en España». Investigaciones Feministas [en línea], 4, 251-265. <http://dx.doi.org/10.5209/ rev_INFE.2013.v4.43892>.

FORWARD, Susan (1986). Cuando el amor es odio: Hombres que odian a las mujeres y mujeres que siguen amándolos. Barcelona: Grijalbo.

García-Vaquero, Micaela G. (2013). «He escrito esta novela para mi propio placer». Periódico Digital El Correo [en línea]. <http://www.elcorreo.com/vizcaya/ rc/20120619/cultura/escrito-esta-novela-para-201206191729.html> [Consulta: 31 enero 2014]. 
Gutiérrez, Jesús (2008). Dinámica del grupo de discusión. Madrid: CIS (Centro de Investigaciones Sociológicas). Cuadernos Metodológicos

Gutiérrez, Saúl (2006). «Género y masculinidad: Relaciones y prácticas culturales». Ciencias Sociales de la Universidad de Costa Rica [en línea], 111-112, 155-175. <http://www.lazoblanco.org/wp-content/uploads/2013/08manual/bibliog/material_ masculinidades_0528.pdf>.

Haeberle, Erwin J. (2005). Atlas de la sexualidad. Madrid: Akal.

Harrow, John (2013). «Mommy porn goes beige, then red hot». The Times [en línea]. <http://www.thesundaytimes.co.uk/sto/news/uk_news/Arts/article1347313.ece> [Consulta: 27 abril 2014].

Herrera, Coral (2010). Construcción sociocultural del amor romántico. Madrid: Fundamentos.

Hite, Shere y Colleran, Kate (1989). Buenos, malos... y otros amantes: Guía de relaciones sentimentales para todas las mujeres. Barcelona: Plaza \& Janés.

IвÁÑEZ, Isabel (2013). "Susto con gusto». El Correo Digital [en línea]. <http:// www.elcorreo.com/vizcaya/20130416/mas-actualidad/sociedad/susto-gusto-201304091823.html> [Consulta: 20 junio 2016].

Illouiz, Eva (2009). El consumo de la utopía romántica, el amor y las contradicciones culturales del capitalismo. Madrid: Katz.

INE. Instituto DE LA Mujer (2001). Género, desarrollo psicosocial y trastornos de la imagen corporal. Madrid. Ministerio de Trabajo y Asuntos Sociales.

- (2008). Guia de coeducación: Sintesis sobre la educación de igualdad de oportunidades entre mujeres y hombres [en línea]. Ministerio de Igualdad. Observatorio para la Igualdad de Oportunidades. <http://www.inmujer.gob.es/observatorios/observIgualdad/estudiosInformes/docs/009-guia.pdf>.

- (2011). Profundizando en el análisis del mito del amor romántico y sus relaciones con la violencia contra las mujeres en la pareja: Análisis cualitativo [en línea]. Ministerio de Sanidad, Servicios Sociales e Igualdad. <http:/www.inmujer.gob.es/areasTematicas/ estudios/estudioslinea2012/docs/Profundizando_analisis_mito_Web_854.pdf>.

James, Erika Leonard (2011a). Cincuentas sombras de Grey. Barcelona: Círculo de Lectores.

- (2011b). Cincuenta sombras más. Barcelona: Círculo de Lectores.

- (2011c). Cincuenta sombras liberadas. Barcelona: Círculo de Lectores.

LAGARDE DE Ríos, Marcela (2011). Los cautiverios de las mujeres: Madresposas, monjas, putas, presas y locas. Madrid: Horas y Horas.

Lombraña, Virginia (2012). "A la sombra de Grey». Abc [en línea]. <http://www. abc.es/estilo-gente/20121122/rc-sombra-grey-201211221246.html> [Consulta: 20 junio 2016].

Lorenci, Miguel (2013). «Lecturas orgásmicas». El Correo Digital [en línea]. <http://www.elcorreo.com/vizcaya/rc/20130418/cultura/lecturas-orgasmicascubitt-201304181828.html> [Consulta: 22 abril 2014].

Maquieira, Virginia (2001). "Género, diferencia y desigualdad». En: Beltrán, Elena, Maquieira, Virginia, Álvarez, Silvina y Sánchez, Cristina. Feminismos. Debates teóricos contemporáneos. Madrid: Alianza Editorial.

Mañana, Carmen (2012). "Receta para cocinar un best-seller porno». El País Digital [en línea]. <http://cultura.elpais.com/cultura/2012/09/11/actualidad /1347375169_659538.html> [Consulta: 22 abril 2014].

Martín, Aurelia (2006). Antropología del género: Culturas, mitos y estereotipos sexuales. Madrid: Feminismos. 
Michelena, Mariela (2012): "Cincuenta sombras de Grey: ¿Un cuento de hadas para adultas?». Mujer Hoy [en línea]. <http://www.marielamichelena.com/index.php/ blog/cincuenta-sombras-de-grey-un-cuento-de-hadas-para-adultas $>$ [Consulta: 20 junio 2016].

Navarro-Pertusa, Esperanza; Barberá, Esther; Reig, Abilio (2003). «Diferencias de género en motivación sexual». Psicothema [en línea], 15 (3), 395-400. <http:// www.psicothema.com/pdf/1078.pdf $>$.

Orbach, Susie y Eichenbaum, Luise (1987). Agridulce: El amor la envidia y la competencia en la amistad entre mujeres. Barcelona: Grijalbo.

Osborne, Raquel (1995). «Sexo, género, sexualidad: La pertinencia de un enfoque constructivista». Papers [en línea], 45, 25-31. <http://www.raco.cat/index.php/ papers/article/viewFile/25262/58545>.

TaYlor, S. J. y Bogdan, Robert (2000). Introducción a los métodos cualitativos. Barcelona: Paidós.

Quelart, Raquel (2012). "Desmontando el mito de "Cincuenta Sombras"». La Vanguardia. <http://www.lavanguardia.com/libros/20120928/54351961387/topicoscincuenta-sombras-grey.html> [Consulta: 31 enero 2014].

Rodríguez, María del Carmen (2003). La configuración del género en los procesos de socialización. Oviedo: KRK.

Rodríguez, Olga Rosalba (2010). «Relaciones entre satisfacción sexual, sociedad y prácticas sexuales». Pensamiento Psicológico [en línea], 7 (14), 41-52. <http://www. redalyc.org/pdf/801/80113673003.pdf $>$.

Ruiz, José Ignacio (2012a). Teoría y práctica de la investigación cualitativa. Bilbao: Universidad de Deusto.

- (2012b). Metodología de la investigación cualitativa. Bilbao: Universidad de Deusto.

"50 sombras de Grey: Muere una joven tratando de imitar las prácticas sexuales descritas en el libro». La Voz Digital de Galicia [en línea], 30 de enero de 2013. <http://www. lavozdegalicia.es/noticia/informacion/2013/01/28/50-sombras-grey-muere-joventratando-imitar-practicas-sexuales-descritas libro/00031359381168928341936. htm> [Consulta: 31 enero 2014]. 